\title{
Exploring the Importance of Team Psychological Safety in the Development of Two Interprofessional Teams
}

\author{
Denise O'Leary \\ Technological University Dublin, denise.oleary@tudublin.ie
}

Follow this and additional works at: https://arrow.tudublin.ie/tfschhmtart

Part of the Business Administration, Management, and Operations Commons, Health and Medical Administration Commons, Interprofessional Education Commons, Organizational Behavior and Theory Commons, and the Social Psychology and Interaction Commons

\section{Recommended Citation}

O'Leary, D.F. (2016). Exploring the Importance of Team Psychological Safety in the Development of Two Interprofessional Teams. Journal of Interprofessional Care, vol. 30, no. 1, pp. 29-34. doi:10.3109/ 13561820.2015.1072142.

This Article is brought to you for free and open access by the School of Tourism \& Hospitality Management at ARROW@TU Dublin. It has been accepted for inclusion in Articles by an authorized administrator of ARROW@TU Dublin. For more information, please contact arrow.admin@tudublin.ie, aisling.coyne@tudublin.ie, gerard.connolly@tudublin.ie.

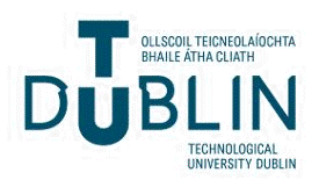




\section{Exploring the importance of team psychological safety in the development of two interprofessional teams}

Denise Fiona O'Leary

Journal Of Interprofessional Care Vol. 30 , Iss. 1,2016

\section{Abstract}

It has been previously demonstrated that interactions within interprofessional teams are characterised by effective communication, shared decision-making and knowledge sharing. This paper outlines aspects of an action research study examining the emergence of these characteristics within change management teams made up of nurses, general practitioners, physiotherapists, care assistants, a health and safety officer and a client at two residential care facilities for older people in Ireland. The theoretical concept of Team Psychological Safety (TPS) is utilised in presenting these characteristics. TPS has been defined as an atmosphere within a team where individuals feel comfortable engaging in discussion and reflection without fear of censure. Study results suggest that TPS was an important catalyst in enhancing understanding and power sharing across professional boundaries and thus in the development of interprofessional teamwork. There were differences between the teams. In one facility, the team developed many characteristics of interprofessional teamwork while at the other there was only a limited shift. Stability in team membership and organisational norms relating to shared decision making emerged as particularly important in accounting for differences in the development of TPS and interprofessional teamwork. 
Keywords: Interprofessional teamwork; team development, team psychological safety, leadership, action research, trust

\section{Introduction}

In an interprofessional team, members are interdependent, share a team identity, understand team roles and responsibilities, integrate their work practices and have clear goals for which they share responsibility and are collectively committed (Reeves et al, 2010). Interprofessional teamwork should be viewed as an emergent process, since to achieve shared understanding, shared goals and interdependency a team must undergo a development process where they learn more about each other, learn to communicate effectively and learn to share responsibility and decision-making (Miller \& Cohen-Katz, 2010). Yet, this development process is rarely explicitly acknowledged within the literature, despite the fact that the importance of understanding the process has been highlighted as a key competency for interprofessional teamwork (Rowthorn \& Olsen, 2014). Instead, interprofessional characteristics are often discussed in static rather than dynamic terms and accounts of interprofessional practice often contain implicit assumptions, rather than explicit recognition, that effective interprofessional teams need time to develop. Poor communication and lack of trust, for example, have been blamed for disharmony among team members but the development of effective communication and trust have been less often studied as emergent characteristics of teams. Accordingly, theories and theoretical frameworks that focus on the development of interprofessional teamwork have received little attention in the literature (Reeves et al 2010). This gap is addressed in this paper which focuses on team climate and its relationship to the development of interprofessional 
teamwork. Accordingly, the theoretical concept of team psychological safety is utilised to underpin an account of the development process in two teams.

Team Psychological Safety

Team psychological safety is a concept that has emerged from the organisational change literature and is characterised as a team climate where people respect and trust each other and are comfortable being themselves. In this type of climate, individuals can take the risk of admitting ignorance or uncertainty without fear of censure or ridicule. Thus they are more likely to hold productive discussions through asking questions, seeking feedback, highlighting failures and sharing information, because their focus is not on self-protection (Edmondson \& Lei, 2014).

Although TPS has not been explicitly linked to the development of interprofessional teamwork, some aspects of TPS, have appeared in accounts of interprofessional teamwork including the importance of a no blame culture (Bateman, Bailey \& McClellan 2003) and feeling comfortable enough to ask naive questions (Charles \& Glennie, 2002). Additionally, reluctance on the part of team members to express their views out of a fear of ridicule has been linked to poor interprofessional teamwork (Morrow, Malin \& Jennings, 2005). This evidence suggests that the link between TPS and interprofessional teamwork merits investigation.

\section{Methods}

Research Approach

Action research is concerned with the generation of knowledge about a social system through change of that system, and is characterised by collaboration with participants and a 
desire to generate practical solutions to context-specific problems. Additionally, one of the basic epistemological principles underpinning action research is to empower participants to make changes on issues of mutual concern (Reason \& Bradbury, 2008). Watts and Jones (2000) have highlighted that action research and interprofessional practice both emphasise the importance of collaboration, democracy, interpersonal relationships, pluralism and reflexivity and thus that action research can be useful in researching and promoting interprofessional teamwork. Action research was used in this project to examine the development of interprofessional teamwork within project teams at two residential care facilities for older people located in Ireland.

\section{Participants}

Two facilities were selected using a typical case purposive sampling method (Miles \& Huberman, 1994). They were chosen because they were private facilities which catered for a mix of cognitively intact and impaired clients and had a typical cohort of care providers. To preserve anonymity the facilities have been given the pseudonyms 'Oakwood Heights and 'Sheltered Cove'.

Following ethical approval from the Research Ethics Committee at the Institute of Technology Tralee, management were approached at both facilities to gain support for the idea of setting up a project team to examine and improve care practices within each facility. Detailed information and consent forms were provided to stakeholders and volunteers were asked to join a team at each facility. As illustrated in Table 1, thirteen care providers joined the team at Oakwood Heights and eleven care providers and one client joined the team at Sheltered Cove. Consistent with an outsider action research approach (Coghlan \& Brannick, 2010), the role of the author within the project was that of an outsider, conducting 
research collaboratively with practitioners within each facility in order to facilitate

organisational change and study the process. Being a member of both teams and chairing most meetings was an integral part of that role.

Table 1: Team Membership at Each Facility

\section{Oakwood Heights}

\section{Care Providers}

1 Clinical care manager

3 Nurses

4 Care assistants

1 Physiotherapist

1 Physiotherapist student on clinical

placement

$2 \mathrm{GP}$ registrars

\begin{tabular}{|ll|}
\hline Other & Other \\
1 Researcher & 1 Researcher \\
& 1 Client living at the facility \\
\hline
\end{tabular}

\section{Cycles of Action Research}

At each of the facilities the teams met approximately once a month over a nine month

period. Each team engaged in cycles of action research where potential improvements in practice were discussed, implemented and evaluated. Changes included the development of a pain assessment tool, setting up a family support group, setting up staff training sessions and the development of information booklets, as illustrated in table 2 .

Table 2: Planned/implemented initiatives at each facility

\begin{tabular}{|c|c|}
\hline Oakwood Heights & Sheltered Cove \\
\hline $\begin{array}{l}\text { 1. Contracture prevention programme discussed but } \\
\text { not implemented } \\
\text { 2. Pain assessment tool developed } \\
\text { 3. Pain medication audit carried out } \\
\text { 4. Family support group set up } \\
\text { 5. Training sessions held } \\
\text { 6. Booklet on recovery from hip replacement } \\
\text { created }\end{array}$ & $\begin{array}{l}\text { 1. Communication policy with GPs } \\
\text { developed but never fully implemented } \\
\text { 2. Training planned but not implemented } \\
\text { 3. Booklet on pain management created } \\
\text { 4. Medication review policy developed but } \\
\text { not implemented }\end{array}$ \\
\hline
\end{tabular}




\section{Data Collection}

Data collection occurred over two years, before, during and after the cycles of action research. In action research, the use of field notes to record data generated in both formal (e.g. meetings) and informal (e.g. conversations with staff and clients) settings is recommended by Coghlan and Brannick (2010), to ensure that actions, reflections and learning are recorded. Additionally, semi-structured interviews, group discussions and questionnaires are commonly used as data collection methods (Coghlan \& Brannick, 2010).

As outlined in Table 3 all of these qualitative methods were used.

Table 3: Data Collection

\begin{tabular}{|c|c|c|}
\hline Data Collected $^{1}$ & $\begin{array}{l}\text { Oakwood } \\
\text { Heights }\end{array}$ & Sheltered Cove \\
\hline $\begin{array}{l}\text { Before Cycles of Action Research Commenced (Project } \\
\text { introduced. Teams not yet set up) }\end{array}$ & July - Nov 08 & Jan - Sept 09 \\
\hline $\begin{array}{l}\text { Field notes: discussions with managing director and care } \\
\text { providers; notes of meetings and activities; my reflections }\end{array}$ & $\begin{array}{l}\text { Recorded on an } \\
\text { ongoing basis }\end{array}$ & $\begin{array}{l}\text { Recorded on an } \\
\text { ongoing basis }\end{array}$ \\
\hline Interviews with clients (Transcribed) & 12 interviews & 7 interviews \\
\hline Group discussion with care providers (Transcribed) & 1 discussion & 1 discussion \\
\hline $\begin{array}{l}\text { During Cycles of Action Research (Teams set up. Meetings } \\
\text { began) }\end{array}$ & Dec 08 - Sept 09 & Oct 09 - May 10 \\
\hline $\begin{array}{l}\text { Field notes: notes of team meetings and activities; notes of } \\
\text { conversations with team members; my reflections; notes of group } \\
\text { reflection }\end{array}$ & $\begin{array}{l}\text { Recorded on an } \\
\text { ongoing basis ( } 6 \text { team } \\
\text { meetings) }\end{array}$ & $\begin{array}{l}\text { Recorded on an } \\
\text { ongoing basis ( } 7 \\
\text { team meetings) }\end{array}$ \\
\hline $\begin{array}{l}\text { Evaluation documents consisting of a list of qualitative questions } \\
\text { to evaluate initiatives }\end{array}$ & $\begin{array}{l}10 \text { distributed, } 6 \\
\text { returned }\end{array}$ & $\begin{array}{l}16 \text { distributed, } 14 \\
\text { returned }\end{array}$ \\
\hline $\begin{array}{l}\text { After Cycles of Action Research Ended (Teams disbanded. } \\
\text { Data gathered afterwards) }\end{array}$ & Oct - Dec 09 & June - Aug 10 \\
\hline $\begin{array}{l}\text { Field notes: discussions with team members and managers; my } \\
\text { reflections }\end{array}$ & $\begin{array}{l}\text { Recorded on an } \\
\text { ongoing basis }\end{array}$ & $\begin{array}{l}\text { Recorded on an } \\
\text { ongoing basis }\end{array}$ \\
\hline Interviews (Transcribed) & $\begin{array}{l}6 \text { team members and } \\
\text { managing director } \\
\text { interviewed }\end{array}$ & $\begin{array}{l}4 \text { team members } \\
\text { interviewed }\end{array}$ \\
\hline
\end{tabular}




\section{FOOTNOTE}

${ }^{1}$ Questionnaire data were also collected before and after cycles of action research (42 at Oakwood Heights and 20 at Sheltered Cove) but the data relate specifically to knowledge and attitudes on pain management and are not utilised in this paper

\section{Data Analysis}

Rigour and reliability were enhanced by the use of a detailed audit trail and by crosschecking the themes with two experienced researchers. Reflexivity was supported through the use of a reflective diary for the duration of the project where the researcher kept note of the potential impact of personal subjectivities. Triangulation was achieved through the use of several data sources as highlighted in Table 3.

The qualitative data were analysed consistent with the approach described by Miles and Huberman (1994) which involves cycles of analysis activity involving data reduction, display and conclusion drawing and verification. The process involved an initial step of reading and re-reading transcripts with the concurrent creation of preliminary themes followed by cycles of analysis using the software package NVivo. During these cycles, data reduction consisted of deconstructing the data into meaningful text segments and coding the segments into themes. The creation of cross-case and within-case data displays facilitated interpretation of emerging patterns and allowed reorganisation of the themes and sub-themes. Integral to the analysis was conclusion drawing and verification using tactics outlined by Miles and Huberman (1994) such as clustering, making comparisons, noting relationships and developing theoretical/conceptual coherence. During data analysis, the literature on team development, and in particular, the theoretical concept of TPS provided a theoretical lens through which to examine the data. 


\section{Results}

As the two teams in this project were newly-formed teams, each of which worked for nine months on a specific task, data collected over that time period highlighted a team development process where, over time, characteristics of interprofessional teamwork developed and strengthened. Data analysis revealed that the development process was catalysed and supported by TPS which created an environment which cultivated power sharing and knowledge co-generation, two aspects of the development of interprofessional teamwork that emerged as important during the study. However, TPS is also emergent and has to be nurtured. This is taken account of in the description of results which first explains how the development of TPS was fostered in both teams, then explores the impact of a growing sense of TPS on the development of the characteristics of interprofessional teamwork and finally highlights the factors that were key in explaining differences between the development of TPS, and thus interprofessional teamwork, in both teams.

Fostering Team Psychological Safety: The importance of leadership behaviour

Action research, the approach taken in the study, is underpinned by an epistemology of empowerment, democracy, collaboration and reflexivity. From a pragmatic perspective this meant that the leadership model utilised within meetings was based on listening actively, using positive language, treating team members with respect, giving positive and constructive feedback, seeking input from all team members, and encouraging group reflection in meetings. This approach was acknowledged by team members in interviews: 
I would have spoken more than I would normally I suppose because you had very good questions that you put forward and you listened to everybody (Team Member 12, Sheltered Cove).

Thus, by striving to be participatory and democratic, the author was encouraging the development of TPS within team meetings. However, TPS development took time. During early meetings at both facilities, team members showed reluctance to discuss sensitive issues. Nevertheless, at Oakwood Heights, an expectation quickly developed that those who spoke in team meetings were listened to with respect, showing that by the end of the study, a psychologically safe space had been created:

I think that by the end of [the study].... there was more respect and everyone facilitated everyone to speak. Whatever idea they had, be it good, bad or indifferent, they were all allowed. There was a trial period i.e. 'will we try this' so everyone's ideas were acknowledged, respected and tried. Some of them were implemented, some of them weren't but everyone seemed satisfied that at least they were given the option to run with it. (Team Member 4, Oakwood Heights)

TPS took longer to develop at Sheltered Cove, but did manifest near the end of the study, evidenced by more open discussion, engagement and critical reflection in meetings. The reasons for the differences in TPS development between the teams are discussed later.

What impact did an emerging climate of TPS have on the development of interprofessional teamwork?

At Oakwood Heights by the end of the study, through sharing power and co-generating knowledge, the team had developed into a unit that were making decisions collaboratively, integrating their work practices, communicating more effectively and were more aware of their own role and others. Thus, the team exhibited many interprofessional team features 
that were absent at the outset. The shift towards interprofessional teamwork took longer and was not as marked in Sheltered Cove. The variations between the teams appeared to be linked to differences in team climate, described in this section, highlighting a role for TPS in fostering interprofessional teamwork.

Power sharing. Shifts in power sharing manifested themselves in different ways. Initially, at Oakwood Heights, the nurse manager on the team made most of the decisions. However with an emerging climate of TPS individuals became more comfortable in asserting themselves in meetings, engaging in shared decision-making, volunteering for responsibility and assigning responsibility to others. Thus, they began to share power and as a result develop a team identity, share responsibility and become interdependent, all characteristics of interprofessional teamwork.

By the end we were all sitting in a room discussing something in common rather than having one person telling everyone else what to do (Team Member 9, Oakwood Heights).

At Sheltered Cove, some shared decision-making occurred as a climate of TPS became more evident in meetings and people became more comfortable expressing their opinion and arguing their position. However, TPS did not develop to the point where team members felt comfortable sharing power in assigning tasks or responsibility and accordingly, the team did not manifest the same level of interdependency and shared identity as the team at Oakwood Heights. Thus, the differences at each facility highlight the importance of creating a team climate where power sharing becomes possible. 
Knowledge co-generation. In Oakwood Heights, articulation of tacit knowledge resulted in co-generation of new knowledge about care practices, as team members became more aware of what others did within the facility, how they did it and how they co-ordinated with others to do it. This occurred because in team meetings increasingly characterised by a climate of TPS, participants began to feel secure enough to verbalise their tacit knowledge. This led to co-generation of knowledge about team roles:

I suppose one big thing that came out of it through our meetings was the amount of assessment tools the physiotherapists had, that I didn't know that they had....I was completely unaware that they even existed because that was their area but [the physiotherapist] talked about them in meetings and answered our questions. I wouldn't have thought to ask those questions normally but it was easy to do [in meetings] (Team Member 4, Oakwood Heights).

Thus one of the characteristics of interprofessional teamwork, an understanding of the roles and responsibilities of other team members, developed at Oakwood Heights. This occurred to a lesser extent at Sheltered Cove where team meetings revealed confusion about role boundaries which were never fully resolved. This was because team members were more reticent about sharing tacit knowledge across professional boundaries until late in the project when a climate of TPS was developing in meetings. The results of the study suggest that TPS provides an atmosphere where co-generation of knowledge is supported which in turn assists the development of interprofessional teamwork.

Why were there different levels of TPS at each facility?

Despite a similar approach to chairing team meetings, underpinned by democracy and empowerment, TPS developed to different extents. Thus, there were other factors that impacted on TPS within each team and consequently the development of characteristics of 
interprofessional teamwork. These were organisational norms and stability of team membership which are discussed in the following section.

The impact of organisational norms on TPS. Organisational norms dictated how professionals engaged with each other at each facility and thus, in team discussions. At Oakwood Heights, shared decision-making in the organisation was much more in evidence, with high input from care assistants in decision-making as highlighted in a group discussion held before cycles of action research commenced:

We all have our input. There has to be input from everyone on the things that we might see that they might not see and there's things that they'd see that we wouldn't see and that kind of thing. You have a team and everyone has some input (Care assistant, Oakwood Heights).

During the study, this interaction was reflected within team meetings where care assistants were just as likely to engage in discussions and decision-making as nurses, GPs and physiotherapists.

At Sheltered Cove on the other hand, care assistants, the team members with less status, self-censored and did not contribute even when their opinions were sought. They stopped attending meetings after meeting 3 and when I explored why, they noted that they did not have decision-making power within the facility which made them wary of engaging in joint decision-making within meetings. This highlights the influence that organisational norms had on team norms.

I think [care assistants] were a little bit afraid....... think [the non-participation of care assistants] was to do with the dynamics in Sheltered Cove itself.... I think they are just unsure of themselves with the nurses. Like if they said something out of place maybe they didn't want to get in trouble (Team Member 9, Sheltered Cove). 
It is possible that if the care assistants continued to attend, they may have become more comfortable engaging in group discussions and decision-making. This proposition is based on the experience a client who joined the team just after the care assistants stopped attending. Organisational norms appeared to impact on her initial interactions with other team members who were reluctant at first to speak openly in front of her:

I noticed that the staff seemed less likely to mention negatives in front of [the client]. I was even doing it myself. For example, the discussion on why we needed to update a policy document. We all downplayed that it was because of a breakdown in communication when she asked (Field notes, February 2010).

Additionally, the client herself expressed a sense of discomfort, suggesting that she did not immediately experience a sense of TPS. However, when interviewed, she explained that near the end of the study, she felt increasingly comfortable engaging in team discussions and decisions. This suggests two things: firstly, that even in situations where TPS is low it can develop which, as highlighted earlier, facilitates the development of interprofessional teamwork; secondly, the development of TPS can lead to the empowerment of previously disempowered members of teams, a feature of effective interprofessional teamwork.

The impact of stability in team membership on TPS.

It is not uncommon for health care teams to be made up of core members and peripheral members and this was reflected at both facilities. At Oakwood Heights there was a core group of six members who attended all or most of the meetings. Having a stable core ensured that we could develop interpersonal relations and trust within this core. This had an impact on TPS allowing it to grow with each meeting.

Due to staffing patterns and staff turnover the situation was different at Sheltered Cove: 
Today one person would come, whatever nurse was in charge, and tomorrow somebody else, so there was no continuity (Team member 11, Sheltered Cove). Individuals who joined the team were often hesitant to immediately engage in discussions. This was articulated most clearly by a team member at Oakwood Heights who reported that by the end of the study she felt comfortable in meetings but felt reluctant to share her ideas during her first meeting because:

I thought they would be laughing at me (Team Member 11, Oakwood Heights). This suggests that if new members are constantly joining the team, there are continuous periods of adjustment, making it difficult to build a climate of TPS. A strong sense of TPS was absent in Sheltered Cove up to the point where meeting attendance began to stabilise at meeting 4 and a core group of three members emerged. Only in meetings 4-7, which were attended by this core group, did the team begin to engage in more open and honest discussion, suggesting a link between a stable team core and TPS, which in turn suggests a link between stability and the development of interprofessional teamwork.

\section{Discussion}

A team 'space' can be viewed as a figurative space superimposed on a physical one. The figurative space is created through the complex sociological interactions of team members while the physical team space is defined by their physical presence. Scott and Hofmeyer (2007) argue that different configurations of physical and social spaces can facilitate or inhibit interprofessional teamwork. By examining newly-formed teams for the emergence of characteristics of interprofessional teamwork, this study highlights the importance of team climate. The study results suggest that within a team space, configurations that facilitate 
interprofessional teamwork are based on a climate of trust and safety between a core group of team members. The construct, TPS, embodies this notion as it describes a team climate where individuals can take the risk of engaging in discussion and decision making without fear of negative consequences such as personal censure, humiliation or risk to their reputation (Edmondson \& Lei 2014).

Successful communication is an essential element of interprofessional teamwork yet communication in healthcare teams with membership from different professional groups can be problematic because of differences in language, perspectives and interests (Matziou et al., 2014). Previous research suggests that TPS allows those with different aims and working practices to find a way to communicate well and work together successfully (Edmondson \& Lei, 2014). This study gives substance to these assertions, as results suggest that TPS allows individuals to feel comfortable enough to give their opinion, ask questions and engage in shared decision-making which allows them to learn with, from and about each other. Thus, TPS can catalyse knowledge co-generation and power sharing which in turn can result in the emergence of attributes of interprofessional teamwork such as shared team identity, an understanding of team roles and responsibilities, shared goals and shared responsibilities.

As previously asserted by Watts and Jones (2000), Action Research can be an effective approach to exploring and nurturing interprofessional teamwork. The results of this study highlight that a reason for this effectiveness is that the emphasis within action research on empowerment, pluralism and democracy fosters the development of TPS and consequently interprofessional teamwork. However, many practitioners attempting interprofessional teamwork do not work within an action research framework, so study results present a 
number of implications for these practitioners. The first is that the importance of TPS should be acknowledged. Team leaders are particularly important in establishing this type of team climate. It has been demonstrated that in teams where team leaders are accessible and democratic TPS is higher and that team leaders can actively encourage TPS by downplaying power differences and acknowledging their mistakes (Faraj \& Yan, 2009). This was borne out in this study and additionally, the importance of a stable team core emerged as important. Thus, team leaders can encourage the development of TPS and interprofessional teamwork by: emphasising the importance of a core group of attendees; encouraging input from all team members; emphasising mutual respect; encouraging empowerment of team members with less status and encouraging discussions on professional roles. Team members can also facilitate TPS development by listening actively, by showing respect, by encouraging others to speak up, by speaking up when needed and by attending regularly.

Teams do not exist within a vacuum; they exist within particular organisational and institutional contexts and influences from outside the team space can impact on the development of TPS within the team space. There is a dearth of empirical evidence to link the characteristics of organisations and the development of interprofessional teamwork (Greenfield, Nugus, Travaglia \& Braithwaite, 2010). The results of this study indicate that open communication and shared decision making is more difficult to achieve within teams embedded in hierarchical organisations where shared decision making is not an organisational norm. Thus, a team must be given time to create an atmosphere of psychological safety which will allow team members to question organisational norms and reconstruct team norms. If a team is allowed to do this, the shared decision-making and 
shared learning that is typical of interprofessional teams becomes possible, even in highly hierarchical organisations.

Previous studies have shown that involving team members in developing team goals, celebrating progress, and developing an understanding of each other's roles are important in building TPS (Faraj \& Yan, 2009). Common sense suggests that these activities necessitate recurring interaction between individuals. It has also been shown that a lack of face-to-face contact can lead to reduced trust and co-operation (Gillespie, Gwinner, Chaboyer \& Fairweather, 2013). Healthcare teams can have high turnover, yet the impact of changing membership on team development is a neglected area of research. The study adds to this limited research by identifying a link between stability in team membership and TPS and a link between TPS and the development of interprofessional teamwork. This suggests that interprofessional teamwork is more likely to develop if there is a core of team members who commit to meeting regularly as a team.

There are a number of limitations that must be taken into account in this study. The study is over five years old, thus some of the issues reported may have changed. In addition, although action research provided a means of examining the process of interprofessional team development, the role of the author as an outsider action researcher meant that there was no researcher observation of the implementation and evaluation of changes in care practices between meetings. Accordingly, the examination of the process of team development was limited to the team space. Additionally, as team members were a small self-selected sample, it is difficult to transfer findings across different settings. Further work is needed to examine the applicability of these findings to other settings and different types of teams. 
In summary, the use of the concept of TPS represents a departure from its utilisation in current literature where it is examined quantitatively at fixed moments in time. The use of an action research approach within this study highlights how TPS can be nurtured and how TPS in turn can catalyse the development of interprofessional teamwork. Further research is needed to extend our understanding of these processes.

\section{Acknowledgements}

The author would like to thank the study participants for their commitment and enthusiasm, Dr Vivienne Brady and Dr Anna-Marie Greaney for their comments on earlier drafts and Dr Clare Rigg and Dr Siobhan Ni Mhaolrúnaigh for their support and feedback during the project.

\section{Declaration of interest}

The author reports no conflicts of interest. The author alone is responsible for the content and writing of the paper.

\section{References}

Bateman, H., Bailey, P., \& McClellan, H. (2003). Of rocks and safe channels: Learning to navigate as an interprofessional team. Journal of Interprofessional Care, 17, 141-150.

Charles, M., \& Glennie, S. (2002). Co-operative inquiry: Changing interprofessional practice. Systemic Practice and Action Research, 15, 207-221. 
Edmondson, A. C. and Lei, Z. (2004). Psychological safety: The history, renaissance, and future of an interpersonal construct. Annual Review of Organisational Psychology and Organisational Behaviour,1, 23-45.

Faraj, S., \& Yan, A. (2009). Boundary work in knowledge teams. Journal of Applied Psychology, 94, 604-617.

Greenfield, D., Nugus, P., Travaglia, J., \& Braithwaite, J. (2010). Auditing an organization's interprofessional learning and interprofessional practice: The interprofessional praxis audit framework (IPAF). Journal of Interprofessional Care, 24, 436-449.

Gillespie, B.M., Gwinner, K., Chaboyer, W., \& Fairweather, N. (2013). Team communications in surgery - creating a culture of safety. Journal Of Interprofessional Care, 27(5), 387393.

Matziou, V., Vlahioti, E., Perdikaris, P., Matziou, T., Megapanou, E., Petsios, K. (2014). Physician and nursing perceptions concerning interprofessional communication and collaboration. Journal Of Interprofessional Care 28(6), 526-533

Miles, M. B., \& Huberman, A. M. (1994). Qualitative Data Analysis, Thousand Oaks, Sage Publications.

Miller, W. L., \& Cohen-Katz, J. (2010). Creating collaborative learning environments for transforming primary care practices now. Families, Systems and Health, 28, 334-347.

Morrow, G., Malin, N., \& Jennings, T. (2005). Interprofessional teamworking for child and family referral in a Sure Start local programme. Journal of Interprofessional Care 19, 93-101.

Reason, P., \& Bradbury, H. (2008). The Sage Handbook of Action Research, London, Sage Publications. 
Reeves, S., Lewin, S., Espin, S. \& Zwarenstein (2010). Interprofessional Teamwork for Health and Social Care, Oxford, Blackwell Publishing.

Rowthorn, V., \& Olsen, J. (2014). All together now: developing a team skills competency domain for global health education. The Journal of Law, Medicine \& Ethics 42(4), 550-563.

Scott, C. M., \& Hofmeyer, A. T. (2007). Acknowledging complexity: Critically analyzing context to understand interdisciplinary research. Journal of Interprofessional Care, $21,491-501$.

Watts, B., \& Jones, S. (2000). Inter-professional practice and action research: commonalities and parallels. Educational Action Research, 8, 377-382. 